\title{
Éditorial
}

\section{Centraliser le marginal}

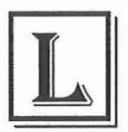

a littérature marginale a plusieurs têtes, comme le monstre mythologique, formidable et tenace. Souvent on considère marginale, l'écriture des femmes, comme dans un milieu de politique et de religion répressive, les écritures des peuples minoritaires et autochtones, celle de la science-fiction, et celles des écrivains clandestins et révoltés, de différence et de déviance, de résistance et d'exclusion sociale. De nos jours, cependant, certaines de ces écritures périphériques ont acquis un degré d'acceptabilité; d'autres, en fait, gravitent de plus en plus vers le centre et ont perdu leur caractère marginal. Certaines ont un lectorat fidèle et grandissant; d'autres font même partie du canon dans les programmes universitaires. On veut être différent. On veut faire du nouveau. On veut se donner une identité par rapport à l'autre. Et donc on est attiré, tenté, séduit par l'œuvre marginale et les tendances à la mode et exotiques. Parfois contre toute raison et sans aucune considération de la qualité de l'œuvre.

Il est très déconcertant de constater ce penchant dans les programmes universitaires de deuxième et troisième cycles. On accepte trop facilement des études sur des auteurs dont la qualité littéraire frôle le médiocre. La justification : c'est différent et peu connu. Souvent, l'étudiant est le seul expert du domaine. On camoufle l'entreprise avec une bonne dose de jargon critique pour y ajouter un semblant de vertu intellectuelle et académique. Aucune préoccupation pour l'intégrité et la responsabilité professionnelle. Parfois des programmes entiers sont axés sur les études du marginal.

Les littératures naissantes dans des contextes minoritaires exemplifient ce malaise. Il faut donner une dimension culturelle à son appartenance. Tous les moyens sont bons pour y arriver. On publie donc n'importe qui. N'importe qui se publie. On est publié, d"ailleurs, parce quil faut épuiser les subventions, ou risquer de les perdre! On se donne des prix, partagés entre les mêmes trente et uns écrivains; après un temps on fait face à la dure difficulté de trouver un digne récipiendaire parmi les usés et les vieux. Où est la relève?... 
On s'offre des congrès; on se fait des revues; on se fait même une ouvre critique. Toutes, des opérations clandestines et intestinales, en famille, entre eux, les trente et uns écrivains. Enfin, on fait une littérature "fondatrice ", se disent-ils. ...Et une littérature marginale s'inscrit ainsi dans l'histoire, champ fertile à thèses de maîtrise et de doctorat.

Sergio Villani

Université York 